\title{
Introduced status of Cyclope neritea (Gastropoda, Nassariidae) in the NW Iberian Peninsula confirmed by mitochondrial sequence data
}

\author{
L. Couceiro, A. Míguez, J. M. Ruiz, R. Barreiro* \\ Área de Ecologia, Facultad de Ciencias, Universidad de La Coruña, Campus A Zapateira s/n, 15071-La Coruña, Spain
}

\begin{abstract}
Confined to a single enclave for more than a decade, the nassariid gastropod Cyclope neritea has expanded its range along the NW Iberian Peninsula (NWIP) region, forming dense populations in several locations. Unintended introductions from imported live shellfish seemed to be the probable vector for this recent proliferation. However, the relative proximity to the edges of the native range of this snail, together with some recent findings in areas similarly invaded by C. neritea (French Atlantic coast), raised the possibility that the species might be present in the NWIP for reasons other than human-mediated transfer. Moreover, it was unknown whether the recent proliferation was due to new independent re-introductions or to the spread from the earlier population. To provide some insight into these questions, we utilized the mitochondrial marker cytochrome oxidase I (533 bp) from individuals collected in 3 localities thought to cover the current known range of the species in the NWIP. Our results strongly confirm the non-native status of C. neritea, pointing to humaninduced introductions as the probable cause for its presence in the NWIP. The Veneto region (Adriatic Sea) is the likely source for the introduced snails, while Manila clam transfers might be the major, even unique, vector of introduction, at least for the more recently settled localities. Recent independent re-introductions, rather than spread from an earlier introduction, appear to be the likely cause for the current proliferation of $C$. neritea within the region.
\end{abstract}

KEY WORDS: Biological introduction · Cyclope neritea · Cytochrome oxidase I - Genetic diversity · Mitochondrial DNA $\cdot$ Nassariidae $\cdot$ NW Iberian Peninsula

Resale or republication not permitted without written consent of the publisher

\section{INTRODUCTION}

Estuarine and coastal systems are among the most heavily invaded systems by exotic organisms (Grosholz 2002). Moreover, it is suspected that the extent of marine invasions may be greatly underestimated due to uncertainty about systematics and historical biogeography (Geller et al. 1997). One example of these limitations is the report of cryptogenic species, i.e. species that are not demonstrably native or introduced, with a frequency that rivals that of known invasions, at least in estuaries and coastal areas under heavy propagule pressure (Carlton 1996). 'Cryptogenic' has been largely applied to organisms with a widespread distribution, as it is often difficult to tell truly cos- mopolitan species from those spread by human action or even from complexes of cryptic species erroneously described as a single one. Yet, even non-cosmopolitan species are occasionally labelled as cryptogenic, for example, when the reputed area of introduction is close to the native range of the species. Under those circumstances, it can be equally difficult to discriminate between human-mediated introduction and natural range expansion, particularly at a time when global warming is recurrently suspected of bringing on changes in range distributions (Helmuth et al. 2006, Parmesan 2006).

The nassariid gastropod Cyclope neritea provides an example of this latter situation. Early surveys (Hidalgo 1917, Nobre 1932) show that the native range of this 
Mediterranean snail enters into the Atlantic coastal areas of the southern Iberian Peninsula as far north as Setúbal, Portugal, and, in a discontinuous distribution (also exhibited by other Mediterranean species), it occurs naturally in the southern coast of the Bay of Biscay (north of the Iberian Peninsula) (see Sauriau 1991 for a detailed summary of published records along Atlantic coasts). Therefore, the southern coast of the Bay of Biscay represented the northern edge of its distribution range until the mid-1970s and early 1980s when $C$. neritea began spreading northwards along the French Atlantic coast up to the entrance of the English Channel (summarized in Bachelet et al. 2004). Human-mediated transport with cultivated bivalves (mostly oysters) from various distant sources, perhaps favoured by a slight warming of the area during the period from 1970 to 1990, was soon identified as the most likely mechanism for this rapid range expansion (Sauriau 1991, Bachelet et al. 2004). However, a recent mitochondrial-based study detailing the genetic structure of those 'new' French populations has renewed the possibility that this gastropod may have been present in the area before the 1970s, thus showing characteristics of a cryptogenic species (Simon-Bouhet et al. 2006).

We provide molecular-based evidence on the status of Cyclope neritea in another area similarly close to the edges of its native distribution range: the NW Iberian Peninsula (NWIP), nearly halfway between the northern limit of the continuous distribution range of this snail in Setúbal and the isolated enclaves historically known to occur in the inner coastal areas of the Bay of Biscay. In this region, a permanent, moderately abundant population of $C$. neritea was first detected in the early 1990s on the southern bank of the Ría de Arousa (Rolán 1992). The species apparently remained largely confined until the early 2000s when it augmented its presence within the region; dense populations are now found at enclaves scattered along the south shore of the Ría de Arousa, and an isolated population has even been recently detected in the adjacent Ría de Pontevedra (Quintela et al. 2006). Rias in NWIP are home to intense aquaculture activity (mostly mussels and several species of clams). The transfer of live animals of diverse ages from various, sometimes very distant, sources has been common practice for years. Therefore, the unintended introduction together with cultivated shellfish seems to be the most parsimonious hypothesis to explain the appearance and expansion of $C$. neritea. However, the relative proximity to its native range, taken together with the aforementioned findings along the
French Atlantic coast, brings up the possibility that $C$. neritea might be present in NWIP rias not solely as a consequence of human-mediated transfer. Moreover, the long time lag since $C$. neritea was first detected in NWIP suggests that new reintroductions, rather than a spread from the earlier population, might account for its recent increase within the region. Finally, we considered that some baseline molecular data were needed at this purportedly early phase of spread, should $C$. neritea continue proliferating along the region in years to come. To give some insight into these 3 questions, we have conducted a mtDNA-based study using individuals from 3 different localities covering the current known range of the species in the NWIP.

\section{MATERIALS AND METHODS}

We sequenced a $533 \mathrm{bp}$ fragment of the mitochondrial cytochrome c oxidase I ( $\operatorname{cox} 1)$ gene from 90 adult specimens collected from 3 different localities (presumed populations). This DNA segment lies within the $658 \mathrm{bp}$ used by the 'Barcode of Life' initiative for animals (Hebert et al. 2003). Sampling in January 2006 included both the area where Cyclope neritea was first detected in NWIP (older location: A Toxa) as well as the 2 edges of its present distribution range within the region (recent locations: Vilagarcía, Poio) (Table 1, Fig. 1). It is important to note that C. neritea has been recorded at various enclaves between $\mathrm{A}$ Toxa and Vilagarcía, but no record of the snail's presence exists between A Toxa and Poio (E. Rolán pers. comm.). All sampling sites were located on or immediately adjacent to clam beds where the substratum consisted of fine sand. $C$. neritea was abundant at the 3 sites and several tens of animals could be easily collected in a few minutes. Laboratory procedures followed those of Bachelet et al. (2004), with only 2 modifications: (1) total DNA was extracted from foot tissue using $10 \%$ Chelex solution (Estoup et al. 1996), and (2) PCR products were sequenced on a Beckman

Table 1. Cyclope neritea. Location information (Universal Transverse Mercator [UTM] co-ordinates) and summary statistics for samples collected from the NW Iberian Peninsula. $N=$ sample size, $N_{\mathrm{H}}=$ number of haplotypes, $S=$ number of segregating sites, $H_{\mathrm{E}}=$ haplotype diversity, $\pi=$ nucleotide diversity. Diversity values are means $\pm \mathrm{SD}$

\begin{tabular}{|lcccccc|}
\hline Population & \multirow{2}{*}{$\mathrm{UTM}$} & $N$ & $N_{\mathrm{H}}$ & $S$ & $H_{\mathrm{E}}$ & $\pi \times 10^{2}$ \\
\hline Vilagarcía & 29T518847177 & 30 & 3 & 12 & $0.517 \pm 0.088$ & $1.003 \pm 0.137$ \\
Poio & 29T526246969 & 30 & 5 & 15 & $0.483 \pm 0.096$ & $0.947 \pm 0.162$ \\
A Toxa & 29T512847037 & 30 & 6 & 18 & $0.731 \pm 0.046$ & $1.102 \pm 0.128$ \\
Total & & 90 & 7 & 19 & $0.614 \pm 0.041$ & $1.121 \pm 0.045$ \\
\hline
\end{tabular}



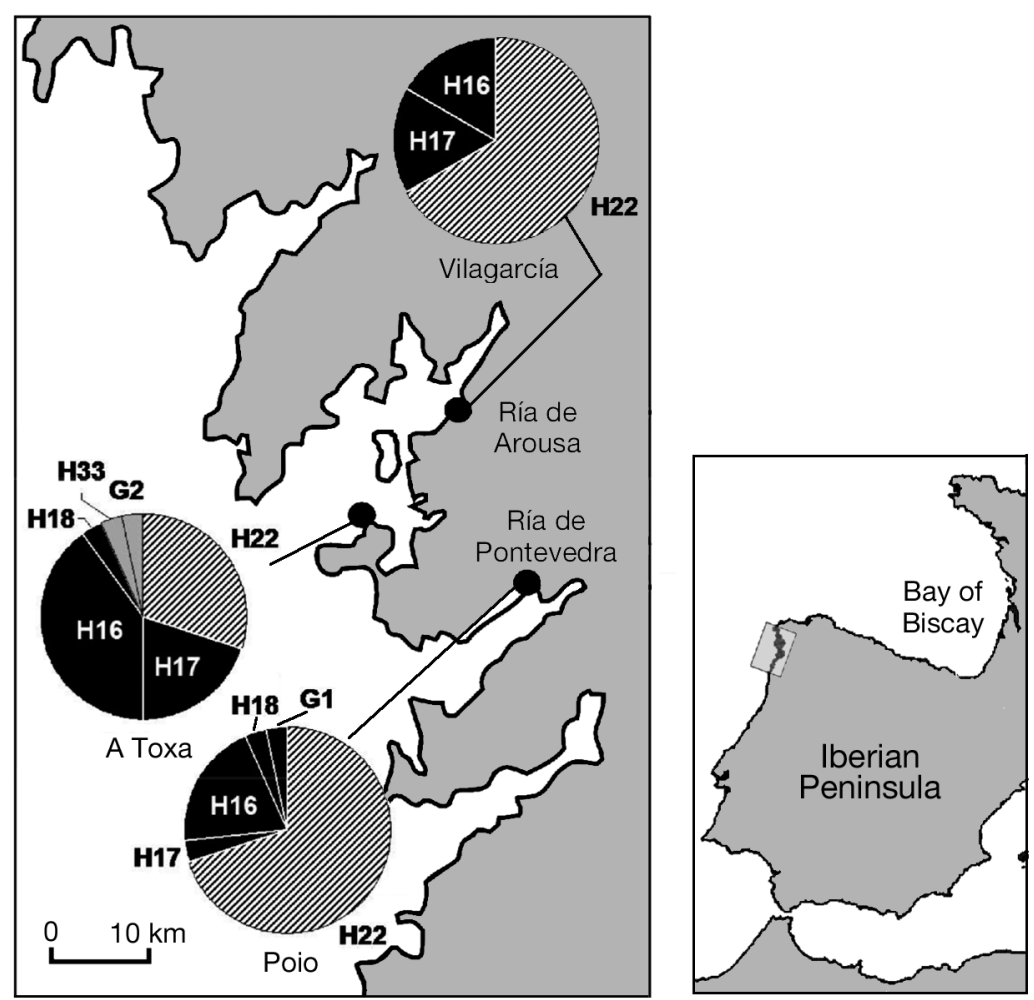

Fig. 1. Cyclope neritea. Sampling sites and haplotype distributions in the NW Iberian Peninsula. To facilitate comparisons, haplotype names and shading of pie charts follow those in Simon-Bouhet et al. (2006). Shading identifies haplotypes from a common genealogical clade: black = clade 2 , hatched $=$ clade 3 , light grey $=$ other haplotypes al. 2003): haplotype diversity $\left(H_{\mathrm{E}}\right)$, Nei's (1987) nucleotide diversity $(\pi)$, number of haplotypes $\left(N_{\mathrm{H}}\right)$, and number of segregating sites $(S)$. The significance of the 2 statistics of molecular diversity among sites was tested using the parametric GT2-method (Hochberg 1974). The haplotype composition of each locality was also analyzed. Because our samples included several haplotypes not previously detected in a wider study by Simon-Bouhet et al. (2006), their genealogical relationship with those already known for the species was inferred by the median-joining network approach implemented in NETWORK version 4.2.0.1 (available at www. fluxusengineering.com/) using the maximum parsimony option to reduce the complexity of the resulting pattern (Bandelt et al. 1999). Finally, regional genetic structure was investigated using analysis of molecular variance (AMOVA, Excoffier et al. 1992); both overall and pairwise genetic differentiation was quantified by calculating $\Phi_{\mathrm{ST}}$ statistics (analogous to $F_{\mathrm{ST}}$ values) and their significance tested using multiple (1023) random permutations with ARLEQUIN version 3.01 (Excoffier et al. 2005).
Coulter CEQ 8000 Genetic Analysis System. Sequence data were aligned using CLUSTAL X with default parameters (Thompson et al. 1997). Sequences were compared with those published in GenBank using the BLAST program (Altschul et al. 1990). Whenever possible, haplotypes were coded according to Simon-Bouhet et al. (2006).

Data analysis included several estimates of DNA polymorphism for each presumed population calculated with the software DNASP version 4.10.4 (Rozas et

\section{RESULTS}

We detected 7 haplotypes from a total of 90 individuals. No indels were detected. Most individuals belonged to 3 haplotypes already described in a previous comprehensive study conducted across a large section of the recognized native range of the species (Simon-Bouhet et al. 2006): haplotype H22 (55.5\%), H16 (25.5\%) and H17 (13.3\%) (Table 2). The remaining 4 were found at very low frequencies and included

Table 2. Cyclope neritea. Haplotype definition and frequency for samples collected from the NW Iberian Peninsula. Only polymorphic sites are indicated. Positions are given in number of base pairs

\begin{tabular}{|lcccccccccccccccccccc|}
\hline Haplotype & N & 1 & 23 & 53 & 104 & 218 & 224 & 254 & 265 & 266 & 292 & 299 & 317 & 338 & 377 & 389 & 425 & 479 & 497 & 503 \\
\hline H22 & 50 & G & C & A & C & G & G & C & C & C & A & G & C & T & G & G & A & A & A & C \\
H17 & 23 & A & - & G & T & A & A & T & - & T & G & A & - & C & - & - & G & - & - & T \\
H16 & 12 & A & - & G & T & A & A & T & - & T & G & - & - & C & - & - & G & - & - & T \\
H18 & 2 & A & - & G & T & A & A & T & - & T & G & - & T & - & - & - & G & G & - & - \\
G1 & 1 & A & - & G & T & A & A & T & T & T & G & A & - & C & - & - & G & - & - & T \\
H33 & 1 & A & T & - & T & A & A & - & - & T & G & - & - & - & - & A & G & - & G & T \\
G2 & 1 & A & T & - & T & A & A & - & - & T & G & - & - & - & A & A & G & - & G & T \\
\hline
\end{tabular}


Table 3. Cyclope neritea. Pairwise comparisons among NW Iberian Peninsula locations. Above diagonal: significance of pairwise differences (GT2-method) in genetic diversity estimates; left/right sides for $H_{\mathrm{E}}$ and $\pi$, respectively. Below diagonal: genetic differentiation among sampling sites in terms of pairwise $\Phi_{\mathrm{ST}}$ values; significance values based on 1023 permutations. $\mathrm{ns}=$ not significant, ${ }^{*} \mathrm{p}<0.05,{ }^{* *} \mathrm{p}<0.01$, ${ }^{* * *} p<0.001$

\begin{tabular}{lccc|} 
& Vilagarcia & Poio & A Toxa \\
\hline Vilagarcia & - & $\mathrm{ns} / \mathrm{ns}$ & ${ }^{* *} /{ }^{*}$ \\
Poio & $-0.030 \mathrm{~ns}$ & - & ${ }^{* *} /{ }^{* *}$ \\
A Toxa & $0.168^{*}$ & $0.212^{* * *}$ & - \\
\hline
\end{tabular}

2 sequences not previously described for the species (coded G1 and G2). Haplotype G1 (GenBank Accession no. EF534201) was genealogically close (1 mutational step) to haplotype H17. Haplotype G2 (GenBank Accession no. EF534202) differed by 1 substitution from the also infrequent haplotype H33 (published by Simon-Bouhet et al. in GenBank under Accession no. DQ985612); both G2 and H33 were separated by 5 or more mutational steps (haplotypic network not shown) from any other sequence (including the 29 haplotypes described by Simon-Bouhet et al. 2006). Haplotype distribution varied across localities (Fig. 1): haplotype H22 dominated the 2 recent locations (Vilagarcía, Poio), while specimens in the older location (A Toxa) were more evenly distributed among haplotypes H16, $\mathrm{H} 17$ and H22. The latter was also the location where the 2 genealogically distant haplotypes G2 and H33 were recorded.

Genetic diversity was consistently high in the 3 sampled localities (Table 1). Nineteen sites were polymorphic over the whole data set and the minimum number of segregating sites per locality was 12 . As a result, the average number of nucleotide substitutions per position was around $1 \%$, both over the whole data set as well as on a per population basis. Despite the overall high level of molecular diversity, nucleotide and haplotype diversities were significantly higher in the older locality as compared with the more recent ones (Table 3). There was also a significant genetic structure among our 3 samples as evidenced by a statistically significant overall $\Phi_{\mathrm{ST}}$ value $(0.131, \mathrm{p}<0.01)$. Pairwise comparisons revealed that this structure was due to the significantly different haplotype composition of individuals from the older locality (Table 3 ). In contrast, the 2 recent localities, despite being located in different rias, were genetically indistinguishable.

\section{DISCUSSION}

In their comprehensive study, Simon-Bouhet et al. (2006) showed that the populations from the native range of Cyclope neritea display very low levels of cox1 genetic diversity almost to the point that most of them are monomorphic or nearly so (mean genetic diversity estimates for their native populations were $0.218,2.4,6.7$ and 0.246 for $H_{\mathrm{E}}, N_{\mathrm{H}}, S$ and $\pi$, respectively). Furthermore, cox1 gene lineages are split across regions within the native range such that locations from the Iberian Peninsula are characterized by haplotypes belonging to their clade 1 . Should the individuals within the 3 sampled NWIP sites be the result of a natural spread from native Iberian Peninsula populations or, as suggested in the French case, be already present at very low densities, it seems reasonable to anticipate that the haplotypes from that clade 1 would be present in them. In contrast, none of our 90 haplotypes belonged to clade 1 or was even genealogically close to it. In addition, $C$. neritea from our 3 localities displayed high levels of genetic diversity. These 2 observations strongly support a non-native origin for our NWIP individuals. Actually, haplotype identities and frequencies at the 2 more recent locations (i.e. a preponderance of haplotype H22 followed by haplotypes from clade 2, see Fig. 1) largely resembled those reported by Simon-Bouhet et al. (2006) for native populations from the Veneto region (Adriatic Sea). Since this region is a major source of the Manila clams Tapes philippinarum imported to shellfish farms in NWIP rias, our results strongly suggest that the transport of Manila clams from the Veneto region may be a major vector for the more recent (early 2000) introduction of $C$. neritea to NWIP rias. Indeed, Manila clam exchanges may even be the unique vector for those introductions. The 2 populations studied by SimonBouhet et al. (2006) in the Veneto region showed genetic diversity levels unusually high for a native population $\left(N_{\mathrm{H}}=5\right.$ to $6, H_{\mathrm{E}}=0.543$ to $0.603, \pi=0.769 \times$ $10^{2}$ to $1.251 \times 10^{2}$ ), but reasonably similar to those recorded in our non-native NWIP localities. Thus, it seems sensible to suggest that the high genetic diversity recorded within NWIP localities may have originated from a unique introduction event from a highly diversified native population (in the Veneto region) rather than from recurrent introductions from multiple sources. A similar explanation has been suggested for some $C$. neritea introductions into French Atlantic coastal areas where exchanges of Manila clams with the Venice Lagoon are likewise frequent (SimonBouhet et al. 2006).

Albeit clearly non-native, the sample from A Toxa shows distinct genetic features. Its dominant haplotypes are also common in the Veneto region. Moreover, the presence of 2 genealogically divergent haplotypes (G2 and H33) resembles the presence of similarly distant haplotypes in the samples from the Veneto region (haplotypes H28 and H29 in Simon-Bouhet et 
al. 2006). However, its haplotype composition is significantly different from that found in the other NWIP locations suggesting that A Toxa may have experienced a different introduction history. A Toxa is located in the area where a permanent, moderately abundant population of Cyclope neritea was first detected in the NWIP more than a decade ago (Rolán 1992). Obviously, we cannot demonstrate that the specimens collected in 2006 descend from that earlier population. Yet, the possibility still exists that $C$. neritea may have been present in A Toxa for a longer time than in the more recent study sites. If so, it may have been the result of a different introduction event or it may even have experienced various re-introductions throughout this time. Interestingly, the origin of that earlier population in the A Toxa area has been linked to oyster transfers from the Venice Lagoon (Rolán et al. 1985, Rolán 1992) rather than to the Manila clam importations identified here as the likely vector for more recent introductions. Irrespective of its precise origin, the distinctive genetic makeup of A Toxa rejects natural spread as a likely mechanism for the recent proliferation of $C$. neritea within the NWIP. This snail has no planktonic larval stage (Gomoïu 1964) and it is often assumed that its potential to disperse is rather limited. Any hypothetical spread within the region should have favoured the occurrence of genetically similar new colonies in geographically close sites. In contrast, A Toxa is significantly differentiated from each of the 2 other locations despite its placement halfway between them.

The potential consequences, if any, of this invasion for the resident community remain uncertain (Bachelet et al. 2004). Cyclope neritea is considered a nuisance in NWIP clam farms where it has reached exceptionally high densities. The conclusion that $C$. neritea has recently proliferated within the NWIP due to humanmediated transport rather than by natural spread of an earlier introduction would imply that any hypothetical control measure should concentrate on avoiding new re-introductions from abroad as well as internal transfers from currently infected areas (e.g. restricting the exchange of clams between NWIP farms).

In conclusion, our results strongly support the nonnative status of Cyclope neritea in NWIP rias and point to human-induced introductions as the probable cause of its presence in this area. The Veneto region is a likely source for the introduced snails and, at least for the more recent locations, Manila clam transfers appear to be the major, even unique, vector. The current proliferation of $C$. neritea within the region probably results from recent independent re-introductions rather than from the spread of the first permanent population detected more than a decade ago in the southern bank of the Ría de Arousa.
Acknowledgements. Funding for this work was provided by the Spanish Ministerio de Educación y Ciencia grant CTM2004-04496/MAR (partially co-founded by FEDER, Fondo Europeo de Desarrollo Regional) and the Xunta de Galicia grant PGIDT05PXIC10302PN. L.C. acknowledges a postgraduate fellowship from Ministerio de Educación y Ciencia (AP2002-0928).

\section{LITERATURE CITED}

Altschul SF, Gish W, Miller W, Myers EW, Lipman DJ (1990) Basic local alignment search tool. J Mol Biol 215:403-410

Bachelet G, Simon-Bouhet B, Desclaux C, García-Meunier P and 6 others (2004) Invasion of the eastern Bay of Biscay by the nassariid gastropod Cyclope neritea: origin and effects on resident fauna. Mar Ecol Prog Ser 276: $147-159$

Bandelt HJ, Forster P, Rohl A (1999) Median-joining networks for inferring intraspecific phylogenies. Mol Biol Evol 16: $37-48$

Carlton JT (1996) Biological invasions and cryptogenic species. Ecology 77:1653-1655

Estoup A, Largiader CR, Perrot E, Chourrout D (1996) Rapid one-tube DNA extraction for reliable PCR detection of fish polymorphic markers and transgenes. Mol Mar Biol Biotech 5:295-298

Excoffier L, Smouse PE, Quattro JM (1992) Analysis of molecular variance inferred from metric distances among DNA haplotypes: application to human mitochondrial DNA restriction data. Genetics 21:479-491

Excoffier L, Laval G, Schneider S (2005) Arlequin ver. 3.0: an integrated software package for population genetics data analysis. Evol Bioinform Online 1:47-50

Geller JB, Walton ED, Grosholz ED, Ruiz GM (1997) Cryptic invasions of the crab Carcinus detected by molecular phylogeography. Mol Ecol 6:901-906

Gomoïu MT (1964) Biologishes Studium der Arten Nassa reticulata (L.) und Cyclonassa neritea (L.) im schwarzen Meer (rumänisher Küstenbereich). Rev Roum Biol (Sér Zool) 9:39-49

Grosholz E (2002) Ecological and evolutionary consequences of coastal invasions. Trends Ecol Evol 17:22-27

Hebert PDN, Ratnasingham S, deWaard JR (2003) Barcoding animal life: cytochrome c oxidase subunit 1 divergences among closely related species. Proc R Soc Lond B Biol Sci 270:S96-S99

Helmuth B, Mieszkowska N, Moore P, Hawkins SJ (2006) Living on the edge of two changing worlds: forecasting the responses of rocky intertidal ecosystems to climate change. Annu Rev Ecol Evol Syst 37:373-404

Hidalgo JG (1917) Fauna malacológica de España, Portugal y las Islas Baleares. Trab Mus Nac Cie Nat 30:1-752

Hochberg Y (1974) Some generalizations of the T-method in simultaneous inference. J Multivar Anal 4:244-234

Nei M (1987) Molecular evolutionary genetics. Columbia University Press, New York

Nobre A (1932) Moluscos marinhos de Portugal. Instituto Zoológico da Universidade do Porto, Imprensa Portuguesa, Porto

Parmesan C (2006) Ecological and evolutionary responses to recent climate change. Annu Rev Ecol Evol Syst 37: 637-669

Quintela M, Couceiro L, Ruiz JM, Barreiro R (2006) Discovery of imposex in the gastropod Cyclope neritea now invading Galicia (north-west Spain). J Mar Biol Assoc UK 86: $1171-1173$ 
Rolán E (1992) Dos especies más de moluscos mediterráneos introducidos en la bahía de O Grove. Thalassas 10:135

Rolán E, Trigo J, Otero-Schmitt J, Rolán-Álvarez E (1985) Especies implantadas lejos de su área de distribución natural. Thalassas 3:29-36

Rozas J, Sanchez-DelBarrio JC, Messeguer X, Rozas R (2003) DnaSP, DNA polymorphism analyses by the coalescent and other methods. Bioinformatics 19:2496-2497

Sauriau PG (1991) Spread of Cyclope neritea (Mollusca: Gastropoda) along the north-eastern Atlantic coasts in relation

Editorial responsibility: Otto Kinne,

Oldendorf/Luhe, Germany to oyster culture and to climatic fluctuations. Mar Biol 109: 299-309

Simon-Bouhet B, Garcia-Meunier P, Viard F (2006) Multiple introductions promote range expansion of the mollusc Cyclope neritea (Nassariidae) in France: evidence from mitochondrial sequence data. Mol Ecol 15:1699-1711

Thompson JD, Gibson TJ, Plewniak F, Jeanmougin F, Higgins DG (1997) The CLUSTALX windows interface: flexible strategies for multiple sequence alignment aided by quality analysis tools. Nucleic Acids Res 25:4876-4882

Submitted: April 11, 2007; Accepted: September 20, 2007 Proofs received from author(s): January 30, 2008 